\title{
Comparison of the harmfulness of smoking tobacco cigarettes versus heat-not-burn tobacco in patients with asthma
}

\author{
Artur Nowak, Rafał Pawliczak \\ Department of Immunopathology, Medical University of Lodz, Lodz, Poland
}

\begin{abstract}
Asthma is a heterogeneous disease characterized by chronic inflammation of the airways with symptoms such as wheezing, shortness of breath, chest tightness and coughing of varying frequency and severity, with varying degrees of airway obstruction. Many factors have a significant influence on the course of asthma, including smoking. The harmful effects of cigarettes have been known for a long time and pose a unique threat to people suffering from asthma. Exposure to passive inhalation of tobacco smoke and active smoking can lead to exacerbation of the disease, wheezing, coughing and shortness of breath. Tobacco smoke irritates the respiratory system and damages the cilia. Continued exposure to cigarette smoke in the environment also increases the risk of other respiratory diseases such as bronchitis, pneumonia and lung cancer.
\end{abstract}

\section{KEY WORDS}

asthma, tobacco cigarette, heat-not-burn tobacco $(\mathrm{HnB})$, cigarettes, nicotine.

\section{ADDRESS FOR CORRESPONDENCE}

Prof. Rafał Pawliczak MD, PhD, Department of Immunopathology, Division of Allergology, Immunology and Dermatology, Faculty of Biomedical Sciences and Postgraduate Training, Medical University of Lodz, 7/9 Zeligowskiego St, Building 2, Room 177, PL-90-752 Lodz, Poland, phone: +48 4227252 75, +48 4227252 76, fax: +48 4227252 75, e-mail: rafal.pawliczak@csk.umed.lodz.pl

\section{INTRODUCTION}

Asthma is a heterogeneous disease characterized by chronic inflammation of the airways with symptoms such as wheezing, shortness of breath, tightness in the chest and cough of varying frequency and severity. Inflammation mainly affects the bronchi. Factors that cause asthma include cigarette smoke, smog, cold air, perfume, and pollen.
According to data from the World Health Organization (WHO), asthma affects nearly 235 million people and in Poland about 4 million people. Every year, smoking in various forms causes many thousands of deaths and is therefore one of the main risk factors for developing asthma.

A cigarette contains an average of 15 to $20 \mathrm{mg}$ of nicotine, and when smoked, about $1 \mathrm{mg}$ of this psychoactive substance penetrates into the blood. Nicotine and staying 
in smoky rooms cause, among other effects, increased secretion of mucus in the respiratory tract, thus promoting the development of chronic inflammation and causing physical dependence. Tobacco smoke is a mixture of 4000 different compounds, many of which are carcinogenic or irritative [1]. Cigarette smoking is still increasing in many low-income, middle-income and even high-income countries, especially among women [2].

\section{HEAT-NOT-BURN TOBACCO PRODUCT}

A heated tobacco product heats up tobacco using a battery-powered heating system [3]. While heating, it generates an aerosol that is inhaled, which contains nicotine, a highly addictive substance [4], smoke, tar, and other chemicals and particles. Heated tobacco products also contain additives not found in tobacco, and are frequently flavored [4]. They heat tobacco leaves at approximately $250-350^{\circ} \mathrm{C}\left(500^{\circ} \mathrm{F}\right)$ [5], a lower temperature than traditional cigarettes [6]. To deliver nicotine from tobacco leaf, heated tobacco products use an embedded or external heat source, or a heated sealed chamber [7]. Heated tobacco products are not electronic cigarettes. Hybrids of heat tobacco products and e-cigarettes can make use of both tobacco and e-liquid [4].

\section{IQOS}

Philip Morris International (PMI) has embarked upon marketing a new-generation heat-not-burn tobacco product, called iQOS (I Quit Ordinary Smoking), which is claimed to have revolutionary technology that heats tobacco instead of burning it. PMI claims that this product gives the real taste of tobacco with no fire, no ash and less smoke, as well as eliminating the undesirable effects related to smoking by reducing the level of toxic chemicals [8]. IQOS consists of three main components - a tobacco stick (called HeatStick), a battery-powered tobacco heating holder and a charger. It is used by inserting the disposable tobacco stick in a slot and then heating it at temperatures below $350^{\circ} \mathrm{C}$. The holder provides heat to a tobacco unit for about 6 minutes or 1214 puffs. The most important difference between iQOS and traditional cigarettes is that whereas tobacco in a regular cigarette is burned at above $600^{\circ} \mathrm{C}$, iQOS heats tobacco up to only $350^{\circ} \mathrm{C}$. It has long been said that iQOS does not release smoke containing unhealthy components due to not burning tobacco at high temperatures, and it prevents users from exposure to the same levels of carcinogens and toxic chemicals found in a conventional cigarette $[9,10]$.

Currently, there are three companies on the world market that produce various systems based on heating tobacco (IQOS - Philip Morris, Glo - British American Tobacco) or on a non-tobacco basis (IFuse Japan Tobacco) $[11]$.

\section{SMOKING AND ASTHMA}

Many studies show that tobacco smoking is associated with poor asthma control, worsening symptoms, impaired response to corticosteroid therapy, accelerated decline in lung function and increased healthcare utilization [3-5]. Smoking is harmful to everyone, while for people with asthma it poses a unique risk because it increases the number of severe exacerbations requiring hospitalization. Tobacco smoking has also adverse effects on human fertility, reproduction and early development $[6,7]$.

Smoking and asthma are the two major public health problems in the world. Active or passive smoking is a factor in the development of asthma and wheezing in the chest. However, the physiopathological mechanisms by which tobacco smoke causes asthma are still poorly understood and require investigation. Active smoking keeps the bronchial tubes inflamed and interferes with asthma control. Therefore, quitting smoking is an important part of managing asthma patients who smoke.

There is no safe concentration of tobacco smoke, which is why it is so important for our health to stop smoking, realize the harmfulness of the addiction and start therapy.

\section{IQOS VS. TRADITIONAL CLASSIC CIGARETTES}

IQOS is certainly an attractive alternative for smokers (Table 1).

Based on the claim that iQOS can prevent secondhand smoke, Protano et al. in 2016 compared passive exposure profiles by measuring submicronic particles (SMPs) generated by conventional cigarettes, iQOS and electronic cigarettes. SMPs emitted from traditional and hand-rolled cigarettes during smoking, as well as accumulated in the respiratory system of passive smokers, were four times higher than those released from electronic and iQOS cigarettes [12].

However, studies by Bialous et al. proved that during the complete combustion (pyrolysis) and thermal decomposition of tobacco, eight volatile organic compounds (VOCs) and thirteen polycyclic aromatic hydrocarbons (PAHs) were released through the IQOS device. The levels of nicotine, benzaldehyde and formaldehyde were $84 \%, 50 \%$ and $74 \%$, respectively, for a conventional cigarette. However, it has been found that acenaphthene is released at $295 \%$ of a regular cigarette and its effect on human health is unknown [13]. 
TABLE 1. Comparison of smoking classic cigarettes with heat-notburn tobacco

\begin{tabular}{|c|c|c|}
\hline Parameter & $\begin{array}{l}\text { Classic } \\
\text { cigarettes }\end{array}$ & $\begin{array}{l}\text { Heat-not- } \\
\text { burn tobacco } \\
\text { products }\end{array}$ \\
\hline Heating temperature $\left[{ }^{\circ} \mathrm{C}\right]$ & 600 & $250-350$ \\
\hline $\begin{array}{l}\text { Acenaphthene polycyclic } \\
\text { aromatic hydrocarbon level }\end{array}$ & Lower $\downarrow$ & Higher $\uparrow$ \\
\hline $\begin{array}{l}\text { Carbon monoxide and formal- } \\
\text { dehyde levels in the air }\end{array}$ & Higher $\uparrow$ & Lower $\downarrow$ \\
\hline $\begin{array}{l}\text { Concentration of pollutants in } \\
\text { the air in closed spaces }\end{array}$ & Higher $\uparrow$ & Lower $\downarrow$ \\
\hline Indoor air quality & Better & Worse \\
\hline $\begin{array}{l}\text { Level of particulate matter } \\
\text { and harmful and potentially } \\
\text { harmful compounds (HPHC) }\end{array}$ & Higher $\uparrow$ & Lower $\downarrow$ \\
\hline $\begin{array}{l}\text { Level of nicotine delivered to } \\
\text { the body }\end{array}$ & Higher $\uparrow$ & Lower $\downarrow$ \\
\hline Mutagenic exposure & Higher $\uparrow$ & Lower $\downarrow$ \\
\hline Appetite for another cigarette & Higher $\uparrow$ & Lower $\downarrow$ \\
\hline $\begin{array}{l}\text { Change in forced expiratory } \\
\text { volume in } 1 \mathrm{~s}\left(\mathrm{FEV}_{1}\right)\end{array}$ & Lower $\downarrow$ & Higher $\uparrow$ \\
\hline Exposure to carcinogens & Higher $\uparrow$ & Lower $\downarrow$ \\
\hline Level of CO exhaled & Higher $\uparrow$ & Lower $\downarrow$ \\
\hline Submicronic particle level & Higher $\uparrow$ & Lower $\downarrow$ \\
\hline PAFR expression & Lower $\downarrow$ & Higher $\uparrow$ \\
\hline $\begin{array}{l}\text { Adhesion of microbes to the } \\
\text { respiratory tract }\end{array}$ & Higher $\uparrow$ & Higher $\uparrow$ \\
\hline
\end{tabular}

\section{INFLUENCE OF IQOS ON PAFR}

Miyashita et al. in a study assessing the relationship between $\mathrm{QQOS}$ and the expression of nasal plaque activating factor $($ PAFR = platelet-activating factor receptor), which is effective in adhering bacteria that cause respiratory infections, observed that PAFR expression was significantly increased in nasal epithelial cells after iQOS exposure and bacterial adhesion. In this way, the number of epithelial cells increased [14].

This study provided information that using the iQOS device contributes to an increase in respiratory infections and multiple asthma attacks.

\section{SMOKING AND NICOTINE ADDICTION}

Vozoris and Stanbrook in their studies in Canada, found that smokers with asthma had a greater nicotine addiction than those who were free from the disease. Women with asthma and smokers had a higher level of nicotine dependence than non-smokers [15], while Brossard et al. found that the maximum ratio of nicotine concentration in IQOS was comparable to CC [16]. There are data suggesting, that $\mathrm{HnB}$ may help in giving up smoking. Interestingly, the use of $\mathrm{HnB}$ may decrease by 4 fold the number of patients returning to traditional smoking. Similar data came from Japan, shownig a decrease of smoking after introducing $\mathrm{HnB}$ products by more than $20 \%$.

\section{SMOKING FREQUENCY}

In another study also conducted in Canada Vozoris et al. used a self-questionnaire, which identified 134,072 responses in 2003 and found the incidence of smoking to be $32.8 \%$ in COPD patients, $21 \%$ in asthmatics and $22.8 \%$ in disease-free individuals [15], while a study by the Bloomberg Foundation found that the percentage of smokers fell from $36 \%$ over 20 years to $24 \%$. However, despite many anti-smoking campaigns and physicians' appeals, the percentage of smokers is still high.

\section{SMOKING AND FORCED EXPIRATORY VOLUME}

Leuppi et al. in their studies proved that prolonged exposure to tobacco smoke in patients with asthma contributes to a decline in lung function: approximately $18 \%$ in forced expiratory volume in $1 \mathrm{~s}\left(\mathrm{FEV}_{1}\right)$ over 10 years [17], while in a recent study by Philip Morris, switching from conventional cigarettes predominantly or completely to HNB products led to higher FEV1\%, decreased exhaled $\mathrm{CO}$ and reduced exposure to carcinogens [18].

It is worth noting that tobacco heating devices are certified and standardized compared to e-cigarettes.

\section{SMOKING AND LUNG CONDITION}

Sohal et al. in 2019 examined the effects of e-cigarettes, tobacco smoke and iQOS on human lungs in vitro. The results of their study show that mitochondrial respiration function changes with iQOS exposure, similar to exposure to e-cigarettes and conventional cigarettes. Mitochondrial dysfunction can further lead to respiratory tract infections, remodeling of the airways and lung cancer by stimulating the mesenchymal transformation of the epithelium (Figure 1), as seen in chronic lung disease. Epithelial to mesenchymal transition (EMT) is a process that allows an epithelial cell to acquire a mesenchymal phenotype through multiple biochemical changes resulting in an increased migratory capacity. During cancer progression, EMT is found to be associated with an invasive or metastatic phenotype. In the laboratory, Dr. Carol Basbaum examined the direct effects of tobacco smoke on lung cell homeostasis, and thereby 


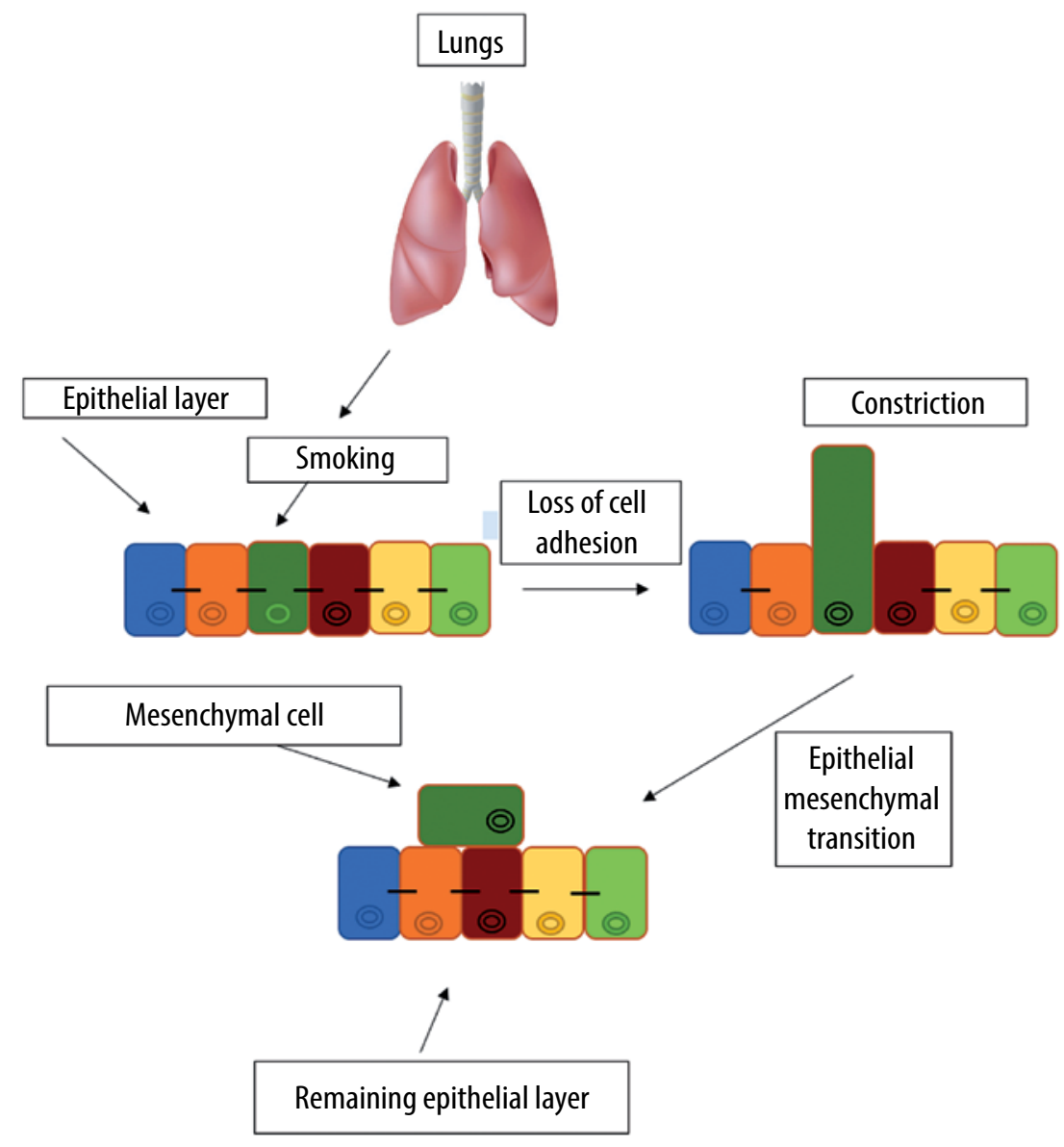

FIGURE 1. Epithelial-mesenchymal transition

defined protumor phenomena induced by smoke, including: loss of cell-cell adhesion, proliferation, inhibition of apoptosis, cell motility, and activation of embryonic signaling pathways [19].

IQOS is also believed to worsen infections by increasing the adhesion of microbes to the respiratory tract. The study by Sohal et al. demonstrated that exposure to iQOS smoke is as harmful as that of cigarettes and electronic cigarettes to human lung cells [20].

Moazed et al. assessed industry data on the pulmonary and immunosuppressive effects of HNB products in near real world conditions and additionally compared the participants with others who continued CC. Industry data did not show any improvement of lung function after three months of transition to IQOS compared with those who continued CC [21].

\section{ECONOMIC ASPECT}

Rahman et al. believe that HNB products are merely signs of a novel tobacco industry strategy to slow progress in tobacco control and that neither the British govern- ment nor medical professionals can compare the effects of changing the form of smoking [22].

\section{CONCLUSIONS}

Smoking in Poland and in the world is a social problem that cannot be disregarded and ignored because it has many negative effects, consequences and diseases. Smoking is the leading cause of preventable death; nearly 6 million people die from it every year. Several studies show that smoking of any kind is associated with poorer asthma control, severity of symptoms and exacerbations. Despite the large number of scientific studies, the exact effects of the harmfulness of $\mathrm{HnB}$ devices are still not fully understood, despite hypotheses that they are less risky to human health than continued smoking of classic cigarettes. Data suggested that $\mathrm{HnB}$ may reduce a health risk for smokers and decrease the number of smoking patients. That is why FDA approoved $\mathrm{HnB}$ as products with reduced health risk. They are certainly an alternative to smokers and are gaining more and more interest, but still require further long-term research and 
evaluation of their impact on the health of people using these devices.

\section{CONFLICT OF INTEREST}

The authors declare no conflict of interest.

\section{REFERENCES}

1. Hoffmann D, Hoffmann I. The changing cigarette, 1950-1995. J Toxicol Environ Health 1997; 50: 307-64.

2. WHO global report on trends in prevalence of tobacco smoking 2015. WHO 2015.

3. Heated tobacco products (HTPs) information sheet". World Health Organization. May 2018.

4. WHO 2019, p. 54.

5. Caputi TL. Industry watch: heat-not-burn tobacco products are about to reach their boiling point. Tobacco Control 2016; 26: 609-10.

6. Li G, Saad S, Oliver B, Chen H. Heat or burn? Impacts of intrauterine tobacco smoke and e-cigarette vapor exposure on the offspring's health outcome. Toxics 2018; 6: 43.

7. MHNZ 2017, p. 4.

8. Bekki K, Inaba Y, Uchiyama S, Kunugita N. Comparison of chemicals in mainstream smoke in heat-not-burn tobacco and combustion cigarettes. J UOEH 2017; 39: 201-7.

9. https://www.pmi.com/smoke-free-products/iqos-our-tobacco-heating-system. 12.01.2019.

10. Ruprecht AA, De Marco C, Saffari A, et al. Environmental pollution and emission factors of electronic cigarettes, heat-not-burn tobacco products and conventional cigarettes. Aerosol Sci Technol 2017; 51: 674-84.

11. Simonavicius E, McNeill A, Shahab L, et al. Heat-not-burn tobacco products: a systematic literature review. Tob Control 2019; 28: 582-94.

12. Protano C, Manigrasso M, Avino P, et al. Second-hand smoke exposure generated by new electronic devices (IQOS ${ }^{\circledR}$ and e-cigs) and traditional cigarettes: submicron particle behaviour in human respiratory system. Ann Ig 2016; 28: 109-12.

13. Bialous SA, Glantz SA. Heated tobacco products: another tobacco industry global strategy to slow progress in tobacco control. Tob Control 2018; 27 (Suppl 1): s111-7.

14. Miyashita L, Grigg J. Effect of the iQOS electronic cigarette device on susceptibility to S. pneumoniae infection. J Allergy Clin Immunol 2018; 141: AB28.

15. Vozoris NT, Stanbrook MB. Smoking prevalence, behaviours and cessation among individuals with COPD or asthma. Respir Med 2011; 105: 477-84.

16. Brossard P, Weitkunat R, Poux V, et al. Nicotine pharmacokinetic profiles of the Tobacco Heating System 2.2, cigarettes and nicotine gum in Japanese smokers. Regul Toxicol Pharmacol 2017; 89: 193-9.

17. Leuppi JD, Steurer-Stey C, Peter M, et al. Asthma control in Switzerland: a general practitioner based study. Curr Med Res Opin 2006; 22: 2159-66.

18. Ludicke F, Ansari SM, Lama N, et al. Effects of switching to a heatnot-burn tobacco product on biologically relevant biomarkers to assess a candidate modified risk tobacco product: a randomized trial. Cancer Epidemiol Biomark Prev 2019; 28: 1934-43.
19. Dasari V, Gallup M, Lemjabbar H, et al. Epithelial-mesenchymal transition in lung cancer: is tobacco the "smoking gun"? Am J Respir Cell Mol Biol 2006; 35: 3-9.

20. Sohal SS, Eapen MS, Naidu VGM, Sharma P. IQOS exposure impairs human airway cell homeostasis: direct comparison with traditional cigarette and e-cigarette. ERJ Open Res 2019; 5: 00159-2018.

21. Moazed F, Chun L, Matthay MA, et al. Assessment of industry data on pulmonary and immunosuppressive effects of IQOS. Tob Control 2018; 27: s20-5.

22. Rahman B, Naile MG, Benay E. An overview of IQOS ${ }^{\circledR}$ as a new heat-not-burn tobacco product and its potential effects on human health and the environment. Turk J Pharm Sci 2019; 16: 371-4. 